\title{
EDUCAÇÃO SUPERIOR NA AMAZÔNIA LEGAL: O CASO DA EXPANSÃO MATO-GROSSENSE
}

\author{
Kelly GIANeZINI \\ Universidade do Extremo Sul Catarinense (UNESC), \\ Criciúma, Santa Catarina, Brasil
}

\begin{abstract}
Resumo: Nas últimas décadas os efeitos da globalização vêm transformando os modos de produção, a forma de socialização e o uso dos conhecimentos. É a partir desta perspectiva que se pretendeu analisar a expansão do ensino superior com relação às diferentes fases (instalação, centralização, interiorização e diversificação) relacionadas ao campo educacional na Amazônia Legal de Mato Grosso (MT) e ao desenvolvimento do Estado (antes e depois da divisão territorial). Metodologicamente, buscou-se: (a) descrever sinteticamente os antecedentes históricos e socioeconômicos, em que ocorreram as transformações que influenciaram os rumos do ensino superior mato-grossense; e (b) tratar do cenário do início do século $X X$ até os dias atuais, abrangendo as fases do ensino superior em MT: da instalação das primeiras Instituições de Educação Superior (IES), passando pela divisão territorial e seus reflexos em MT, até a diversificação do ensino ocorrida no início do século XXI.

Palavras-chave: Educação Superior. Universidade. Brasil. Expansão.
\end{abstract}

INTRODUÇÃO

Nas últimas décadas os efeitos da globalização "[...] denotam a escala crescente, a magnitude progressiva, a aceleração e o aprofundamento do impacto dos fluxos e padrões inter-regionais de interação social" (HELD; MCGREW, 2001, p. 13). Globalização também se refere a uma mudança na"escala 
da organização social que liga comunidades distantes e amplia o alcance das relações de poder nas grandes regiões e continentes do mundo" (p. 15), produzindo distintas consequências. Além disso, os efeitos da globalização vêm transformando não apenas os modos de produção, como também a forma de socialização e o uso dos conhecimentos.

Considerando as novas exigências impostas pelo desenvolvimento econômico por melhor qualificação de profissionais para o mercado de trabalho e, também, maior demanda na prestação de serviços, questiona-se: especialmente nos últimos anos, é possível perceber que as transformações da economia globalizada funcionaram como força propulsora do processo de expansão do ensino superior em Mato Grosso? Se sim, pode-se identificar a existência de diferentes fases em tal expansão? Quais fatores impulsionaram a passagem de uma fase para outra?

O objetivo deste artigo é analisar a expansão do ensino superior com relação às diferentes fases (instalação, centralização, interiorização e diversificação)' desenvolvidas por Neves, em 1993, relacionadas ao campo educacional na Amazônia Legal mato-grossense e ao desenvolvimento do estado de Mato Grosso, antes e depois da divisão territorial.

Metodologicamente, buscou-se descrever sinteticamente (a) os antecedentes históricos e socioeconômicos, em que ocorreram as transformações que influenciaram os rumos do ensino superior mato-grossense. Em seguida, (b) trata-se do cenário do início do século XX até os dias atuais, abrangendo as fases do ensino superior em Mato Grosso: da instalação das primeiras Instituições de Educação Superior, passando pela divisão territorial e seus reflexos em MT, até a diversificação do ensino ocorrida no início do século XXI.

ANTECEDENTES HISTÓRICOS E SOCIOECONÔMICOS DO CAMPO EDUCACIONAL NO antigo estado de Mato Grosso

O primeiro sinal de curso superior em Mato Grosso surgiu em 1808, por meio de uma aula prática em anatomia e cirurgia, oferecida em Vila Bela da Santíssima Trindade, que depois se transformou em Curso Prático de Anatomia e Cirurgia (MOURA, 1978; SIQUEIRA, 2002; DORILEO, 2005; VELOSO; SILVA; BERALDO, 2006).

Embora tenha durado apenas quatro anos, esse curso foi importante, pois demonstrou a necessidade de que fosse ofertado um ensino técnico especializado, capaz de atender às reais necessidades médicas da população, que apresentavam inúmeras doenças tropicais, típicas da região, e eram 
causadas pelas constantes enchentes. Esse curso, também chamado de Curso Superior de Anatomia, foi concebido na administração do penúltimo governador da capitania mato-grossense, João Carlos Augusto d'Oeynhausen de Gravenberg, que governava simultaneamente as capitanias do Pará e do Ceará. Em sua administração, fundou o hospital São João dos Lázaros - a atual Santa Casa de Misericórdia de Cuiabá, para abrigar os doentes e servir, igualmente, de laboratório prático aos estudantes do Curso de Anatomia - e a Escola de Aprendizes Marinheiros, cujo objetivo era capacitar jovens para a guarnição dos rios Paraguai, Paraná e Coxipó (SIQUEIRA, 2002).

Tais iniciativas implantadas pelo governador exigiram altos investimentos gerando um significativo déficit. O governador seguinte, Francisco de Paula Magessi Tavares de Carvalho, transferiu a capital Vila Bela da Santíssima Trindade para Cuiabá (FERREIRA, 2004). Essa nova e definitiva capital mato-grossense assistiria, ao longo do século $X X$, a algumas iniciativas que resultaram na criação da Universidade Federal de Mato Grosso (UFMT).

Ainda que fatos nefastos, como a Guerra do Paraguai e a epidemia de varíola, ocorridas em um intervalo de quatorze anos (1864-1878), tenham acometido os nativos de Mato Grosso, chama-se a atenção para duas consequências positivas refletidas na educação mato-grossense.

Considerando que cada província tinha o direito de regulamentar e promover a educação primária e secundária, e, com o intuito de reanimar a população e superar as baixas (RIBEIRO, 1979; NASCIMENTO, 1998; FRANCISCO, 1998), foram organizados em Cuiabá dois liceus cujo ensino era público e secundário. O Lyceu de Línguas e Sciências (1879/1880), e o Lyceu Cuyabano (1880), com os cursos de História, Latim, Inglês, Francês, Filosofia, Moral e Retórica. Posteriormente, esse último passou a conferir grau de Bacharel em Ciências e Letras conforme o Decreto n³.890, de 1901.

O fim da guerra trouxe, como consequência positiva, a reabertura dos canais fluviais, fato que possibilitou o intercâmbio de conhecimento entre viajantes e nativos.

Em 1894, destaca-se a chegada dos Salesianos em Mato Grosso, a missão salesiana como foi chamada. Como era necessário o preparo de pessoal mais diversificado, foram criadas quatro oficinas profissionalizantes em 1898: de alfaiataria, ferraria, carpintaria e curtição de couro. Além disso, foram estabelecidas várias escolas de nível primário, secundário e profissionalizante, das quais as mais conhecidas são: Liceu Salesiano São Gonçalo, futuro Colégio São Gonçalo (1895); Colégio Santa Teresa (1899); Escola Agrícola de Santo Antônio (1908); Colégio Dom Bosco (1929); Escola Industrial (1940/1942); e 
Escola Rui Barbosa (1964). A partir de 1902, o Colégio São Gonçalo, do mesmo modo que o Lyceu Cuyabano passou a conferir grau de Bacharel em Ciências e Letras (SIQUEIRA, 2002).

Em 1899 foi formada a Sociedade Internacional de Estudos Científicos, cujo objetivo era desenvolver a História e a Geografia do Brasil e de Mato Grosso. Esta sociedade forneceu importantes instrumentos metodológicos, históricos e geográficos para a Comissão Rondon, "que percorreu 1.600 quilômetros de mata cerrada, com rios largos, povos indígenas e poucos mapas para guiarem os homens nesta empreitada" (CATELLI, 2007, p. 334), com o propósito de integrar o sertão à nação brasileira.

Apesar de ter sido fundada a Escola de Aprendizes Artífices (atual Instituto Federal de Educação, Ciência e Tecnologia de Mato Grosso - IFMT), cujo período de existência foi de 1808 até 1910, houve apenas iniciativas fragmentadas de ensino superior no estado de Mato Grosso. Isto se deve, provavelmente, à herança deixada pelos exploradores espanhóis, e, mais tarde, àquela deixada pelos bandeirantes, cujo único objetivo era o de explorar as terras mato-grossenses.

AS FASES DO PROCESSO DE EXPANSÃO DO ENSINO SUPERIOR em Mato Grosso

O ensino superior em Mato Grosso tem passado por diferentes fases de desenvolvimento associadas às mudanças no processo de desenvolvimento econômico, político e cultural, porém em circunstâncias e períodos históricos distintos, de outros estados brasileiros.

INSTALAÇÃO DO ENSINO SUPERIOR EM MATO GROSSO

Nas primeiras décadas do século XX, Mato Grosso começa a acenar para as experiências de ensino superior. A esse respeito, Dorileo (1982) cita algumas tentativas de criação de IES, tanto em Cuiabá quanto na parte sul do estado, entretanto, elas não obtiveram êxito. Trata-se da Escola Superior do Comércio (1914), o primeiro curso de nível superior em Cuiabá, e que, em 1929, recebeu a denominação oficial de Escola Comercial Antônio Corrêa.

Fatos marcantes na década de 1930 foram as tentativas de implantação (1934) da Faculdade de Direito de Cuiabá (extinta em 1937) e da Faculdade Mato-Grossense de Farmácia e Odontologia, estabelecida em Campo Grande (também extinta pouco tempo depois). Convém salientar que a Faculdade 
de Direito de Cuiabá foi "criada por iniciativa de um grupo de bacharéis. Essa instituição teve uma história conturbada, em decorrência de consecutivos processos de interrupções e de reinício das atividades acadêmicas" (VELOSO; SILVA; BERALDO; 2006).

No Brasil de 1945 e 1964 (período populista), ocorreu o processo de integração do ensino superior, que desencadeou o surgimento de novas universidades, por meio de agrupamentos de faculdades isoladas pré-existentes, ocasionando uma significativa expansão do número de matrículas (OLIVEN, 2002). Um dos desdobramentos desse processo, no que tange ao ensino superior em Mato Grosso, veio a ser refletido, anos depois, por ocasião da própria concepção da UFMT, que sofreria influência desse projeto, já que nasceu a partir da união de dois institutos.

Impulsionadas pelo desejo da população mato-grossense em ter uma universidade, nas décadas de 1950 e 1960, houve, em Cuiabá, a luta pela (re) implantação (1952), autorização (1956) e reconhecimento (1959) da Faculdade de Direito de Mato Grosso (FDMT), futuramente integrada à Universidade Federal de Mato Grosso (UFMT). Em Campo Grande, em 1961, foi criada a Faculdade Dom Aquino de Filosofia, Ciências e Letras (FADAFI), embrião das Faculdades Unidas Católicas de Mato Grosso (FUCMT), mais tarde transformada em Universidade Católica Dom Bosco (UCDB).

Nesse momento, faz-se necessário trazer à tona o contexto político e social em que estavam inseridas as primeiras iniciativas de instalação de ensino superior. No início do século XX, a situação política do Estado de Mato Grosso era caótica, não existiam garantias individuais, proliferavam boatos de rebeliões que implicavam assassinatos dos prováveis rebeldes. Esses eram os principais indícios da batalha que se travaria nas décadas seguintes, em prol da divisão/separação do Estado de Mato Grosso.

A disputa entre dois grandes blocos representados por partidos políticos, Republicano Conservador e Republicano Mato-Grossense, foi um dos fatores decisivos para essa instabilidade política (SILVA, 1996, p.141). A questão também se vinculava aos problemas econômicos que o Estado enfrentava: "no início do século perdíamos o comércio da borracha por inépcia de nossos dirigentes, o mesmo ocorria [...] com o mate [...] a luta pelo poder econômico e político se fez nestas duas frentes, tendo, de um lado, a oligarquia do centro e, de outro, a do sul" (SILVA, 1996, p. 237).

A situação conflitante em que se encontravam as duas cidades mato-grossenses, Cuiabá (no Centro) e Campo Grande (no Sul), tornava-se 
insustentável. Qualquer manifestação feita por um dos lados era tomada como provação.

Nesse contexto, observa-se que, no campo da educação superior, entre 1961 e 1969, houve uma profusão de iniciativas contínuas e descontínuas, de criação das faculdades que, mais tarde, passariam a integrar as universidades públicas (UFMT e a Universidade Estadual de Mato Grosso UEMT), como, por exemplo, o Instituto de Ciências e Letras de Cuiabá (ICLC) e o Instituto de Ciências Biológicas de Campo Grande (ICBCG).

Portanto, na mesma década (1960), a educação superior no antigo estado de Mato Grosso era assim representada: (a) por uma IES confessional comunitária, em Campo Grande, a FADAFI (que criaria anos depois a Faculdade de Direito - FADIR), e (b) a outra IES pública-estatal, em Cuiabá (Faculdade de Direito de Mato Grosso - FDMT), que seria incorporada pelo ICLC e, posteriormente, integraria a UFMT (FERNANDES, 2003).

\section{Centralização do ensino superior em Mato Grosso}

A fase de centralização do ensino superior em Mato Grosso ocorreu em dois momentos. O primeiro momento da fase de centralização corresponde ao que se denominou de fase de centralização bipolarizada ocorrida até a divisão do estado. Esta fase refere-se à peculiaridade do ensino superior concentrar-se nas cidades de Cuiabá e Campo Grande. Cabe destacar que, em breve, a última seria a capital do novo estado: Mato Grosso do Sul (MS). O segundo momento, a fase de centralização, ocorreu nas cidades de Cuiabá e Cáceres, após a divisão do estado.

Sendo assim, a centralização revela-se "bipolarizada" nos anos que

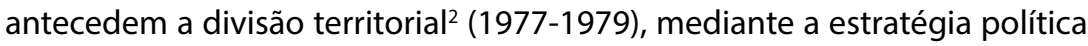
estadual que consistia em pressionar o governo central a autorizar a implantação de uma universidade federal em Cuiabá (a UFMT) e uma universidade estadual em Campo Grande (a UEMT).

Apesar da crise separatista instaurada em todo o estado ter sido iniciada anos antes, é com a "rixa" pela instalação da primeira universidade que se torna irreversível o processo de divisão. Em setembro de 1969, "estimulado pelos políticos do sul e, atendendo à demanda dessa região [...] e, de certo modo, uma estratégia política de conciliação entre as duas regiões" (BITTAR; RODRIGUEZ; ALMEIDA, 2006, p. 24), o governador do Estado de MT, o sul mato-grossense Pedrossian, criou a primeira universidade estadual, a UEMT, em Campo Grande. 
Ironicamente, foi em Campo Grande, em 12 de dezembro de 1969, que o então presidente Emílio Médici enviou o projeto de lei ao Congresso Nacional, cuja aprovação resultaria na criação da primeira universidade federal do Estado, a Universidade Federal de Mato Grosso (UFMT), com sede em Cuiabá (VELOSO; SILVA; BERALDO, 2006).

Em resposta a isso, "a autorização para o funcionamento da UEMT ocorreu por meio do Decreto Presidencial no 67484, de 04 de novembro de 1970 (BITTAR; RODRIGUEZ; ALMEIDA, 2006). Praticamente um mês depois, o projeto da UFMT foi transformado na Lei n० 5.647, de 10 de dezembro de 1970 (VELOSO; SILVA; BERALDO, 2006). Nascia assim a UFMT.

Um aspecto importante refere-se à lacuna que houve, no campo do ensino superior, no Estado de Mato Grosso até o ano de 1970. Até essa data, "os mato-grossense sentiam o desgosto de viver no estado que era o único da federação que não possuía universidade federal" (VELOSO; SILVA; BERALDO, 2006, p. 27). Assim, no mesmo ano, seriam fundadas duas universidades públicas e gratuitas: uma estadual e outra federal.

Por conseguinte, alguns acontecimentos históricos marcaram o cenário do ensino superior mato-grossense, na década de 1970, e realçaram os contrastes culturais e educacionais das duas regiões.

Em Cuiabá, a criação da UFMT envolveu, ao longo da década supracitada, diferentes acontecimentos: (a) fusão entre o ICLC e a Faculdade de Direito, dando, finalmente, origem a UFMT; (b) criação da Fundação Universidade da Selva - UNISELVA; (c) inauguração da cidade universitária; e (d) criação do Instituto Cuiabano de Educação (ICE);

Por sua vez, em Campo Grande, ocorreu a criação da Universidade Estadual de Mato Grosso (UEMT), ${ }^{3}$ tendo sido federalizada nove anos depois de sua criação, passando a se chamar Universidade Federal de Mato Grosso do Sul (UFMS), pela Lei n 6.674, de 05 de julho de 1979 (BITTAR; RODRIGUEZ; ALMEIDA, 2006). Além disso, faculdades privadas se estabeleceram: Faculdade de Ciências Econômicas, Contábeis e Administração (FACECA); Faculdade de Serviço Social (FASSO); Centro de Ensino Superior Prof. Plínio Mendes dos Santos (CESUP), futura Universidade para o Desenvolvimento Regional do Pantanal (UNIDERP); e em Dourados a Sociedade Civil de Educação da Grande Dourados (SOCIGRAN), futuro Centro Universitário da Grande Dourados (UNIGRAN).

Nesse momento histórico de irreversível processo de divisão territorial, que centralizou o ensino superior da parte sul em Campo Grande, ocorreu em Cáceres, a instalação do Campus Avançado do Projeto Rondon (1973-1989) 
e a instalação do Instituto de Ensino Superior de Cáceres (IESC 1978) que, após passar por várias denominações - Fundação Centro Universitário de Cáceres (FCUC 1985), Fundação Centro de Ensino Superior de Cáceres (FCESC 1989) e Fundação de Ensino Superior de Mato Grosso (FESMAT 1992) - transformou-se em Universidade do Estado de Mato Grosso (UNEMAT 1993).

Este fato é relevante, pois no período que sucede a divisão territorial até os anos de 1990, uma nova centralização estava em curso, representada pela concentração de novas IES privadas na microrregião de Cuiabá (VELOSO; SILVA; BERALDO, 2006) e pela luta para a implantação de uma nova universidade pública, a Universidade do Estado de Mato Grosso, em Cáceres (ZATTAR; TEIXEIRA; ARTIOLI, 2008).

Ao final desse período, Mato Grosso estava se transformando em uma nova fronteira agrícola brasileira, impulsionada economicamente pelo incentivo governamental, e, culturalmente, pela migração sulista (SANTOS, 1993; CASTRILLÓN FERNANDEZ, 2007). Era uma situação distinta da que ocorria no país, já que a "sucessão de 'planos econômicos', por sua vez, não conseguiu controlar a inflação, principal indicador da deterioração da economia" (OLIVEIRA, 2005, p. 313).

Interpretam-se estas iniciativas como sinais de uma nova fase vindoura, incluindo a UNEMAT, que, como universidade pública estadual criada na cidade de Cáceres, abriu caminho para a interiorização do ensino superior em Mato Grosso, sendo juntamente com a UFMT, uma das principais responsáveis por este processo.

INTERIORIZAÇÃO DO ENSINO SUPERIOR EM MATO GROSSO

A fase seguinte que sucede a da centralização pode ser comparada, analogamente, a uma encruzilhada. No questionamento de Oliveira (2009, p. 4), "¿Qué caminos debe emprender una universidad para que, sin renunciar a la cultura ni a las identidades locales, pueda establecerse como factor de emulación de la racionalidad política en una sociedad dentro de la era del conocimiento?"4

Ao aplicar este questionamento à realidade mato-grossense, as respostas parecem surgir a partir da década de 1990, quando o processo de expansão se deu pela via da interiorização. Registrou-se a concepção dos múltiplos campi das universidades federal e estadual, assim como o surgimento de outras faculdades privadas. 
A expansão para o interior ocorreu num período de transformações econômicas e socioculturais, provocadas pelo desenvolvimento agrícola e pelo segundo momento do processo migratório. Além disso, nesse período, o Produto Interno Bruto (PIB) do estado saltou de $\mathrm{R} \$ 7.700 .032,63$ em 1990, para $\mathrm{R} \$ 13.428 .289 .000,00$, em 2000 (IPEA, 2009). O Índice de Desenvolvimento Humano (IDH) $(0,685$ em 1991) também apresentou relativo aumento (0,773 em 2000), apesar de o índice de gini (0,60 em 1991) ter permanecido praticamente estável (0,68 em 2000).

Esse contexto foi fundamental para que a UFMT e a UNEMAT expandissem ações consideradas inovadoras por praticamente todas as regiões do Estado, mediante a criação de: (i) novos campi; (ii) núcleos pedagógicos; (iii) polos (municípios escolhidos para atuarem como polos de educação a distância) (ALONSO, 2005; VELOSO; SILVA; BERALDO, 2006; ZATTAR, 2008); (iv) cursos emergenciais (não permanentes); (v) cursos na modalidade Parcelada; e (vi) turmas especiais. ${ }^{5}$

Essas ações peculiares foram necessárias, nesse período, em virtude das amplas dimensões territoriais do estado, composto de municípios carentes de infraestrutura, onde, segundo Beraldo (2005, p. 05) "a investigação das propostas alternativas para a interiorização das ações das universidades públicas se torna mais imperativa".

Na UFMT, estas propostas estão associadas ao desenvolvimento de cursos na modalidade parcelada e com turmas especiais, além dos campi fora da sede em Cuiabá: Rondonópolis, Barra do Garças e Sinop; e das unidades fora de sede: Água Boa, Primavera do Leste, Campo Verde, Tangará da Serra e Juína. Isto fica evidente em sua missão, recentemente reformulada:"produzir e socializar conhecimentos, contribuindo com a formação de cidadãos e profissionais altamente qualificados, atuando como vetor para o desenvolvimento regional socialmente referenciado" (PDI6/UFMT, 2008, p. 46).

Já com relação à UNEMAT, diferentes grupos - leigos, religiosos e políticos - uniram forças em prol da instalação de núcleos. Com a transformação em universidade, os seis núcleos pedagógicos existentes na época foram elevados à condição de campi. Assim, a UNEMAT (re) nasceu como uma instituição multicampi e multinucleada. Seu lema "Do interior para o Interior" evidenciaria sua missão em Mato Grosso, reforçada pela sua própria missão institucional de "levar a educação superior ao interior do estado de Mato Grosso por intermédio de cursos e programas especiais e com características próprias" (PDI/UNEMAT, 2008, p. 34). 
Enfatizam-se ainda iniciativas locais, que culminaram, em 1994, com o credenciamento da primeira universidade privada do estado, a Universidade de Cuiabá (UNIC) e o estabelecimento da Faculdade Municipal de Nova Mutum (FAMUNM), futura UNINOVA (União do Ensino Superior de Nova Mutum). ${ }^{7}$

No ano seguinte ocorreu o credenciamento sucessivo de várias IES: Faculdade de Tecnologia do Vale do Araguaia (FATEV) em Barra do Garças; Faculdade de Educação de Alta Floresta (FEAFLOR); e Faculdade de Ciências Contábeis de Alta Floresta (FACTERFLOR).

Nesse período, destaca-se a absorção da faculdade privada Centro de Ensino Superior de Tangará da Serra (CESUT) pela UNEMAT (ZATTAR; TEIXEIRA; ARTIOLI, 2008), fato que suscitou tensão entre agentes sociais.

Em 1997, foi a vez da implantação das Faculdades Integradas de Rondonópolis (UNIR), da Faculdade de Administração de Alta Floresta (FAFLOR) e da União das Faculdades de Educação de Alta Floresta (UNIFLOR). Neste mesmo ano, destaca-se, ainda, a instalação da agência fomentadora de pesquisa de Mato Grosso, a Fundação de Amparo à Pesquisa do Estado de Mato Grosso (FAPEMAT). Sua finalidade se baseava no"amparo e o desenvolvimento da pesquisa humanística, científica e tecnológica em MT"e, paulatinamente, apoiou e incentivou o desenvolvimento das IES.

Subsequentemente ocorre a instalação da Faculdade Afirmativo (FAFI), em Cuiabá; da Faculdade de Ciências Jurídicas, Gerenciais e Educação Superior de Sinop (FIS), em Sinop; da Faculdade de Ciências Sociais de Guarantã do Norte (FCSGN), em Guarantã do Norte; e da Faculdade de Direito em Tangará da Serra (FDTS), em Tangará da Serra, sendo esta última mantida pelos mesmos mantenedores da UNIC.

Por fim, ressalta-se a criação da primeira IES confessional, privada e filantrópica do estado, a Faculdade Católica Rainha da Paz de Araputanga (FCARP); e, em especial, o credenciamento definitivo, em 1999, da UNEMAT, em todos os campi no interior do Estado: Sinop, ${ }^{8}$ Alta Floresta, Alto Araguaia, Colíder, Pontes e Lacerda, Barra do Bugres, Tangará da Serra, Nova Xavantina e Luciara.

\section{DiVERSIFICAÇÃo do SISTEMA do ENSINO SUPERIOR EM MATO GROSSO}

No início do século XXI tem-se a fase de diversificação das IES, com a ocorrência de acontecimentos de diversas naturezas nos setores público e privado, tanto na capital, como no interior. (a) Setor público (Centro Federal de Educação Tecnológica - CEFETs, Instituto Federal de Educação, Ciência e 
Tecnologia - IFECTs e Centro de Educação Profissional e Tecnológica de Mato Grosso - CEPROTEC).

De acordo com o Balanço Econômico 2005, o PIB de MT cresceu 9,8 vezes em relação à média nacional em 2003. Em relação ao fomento da economia no setor comercial e industrial, foram criados aproximadamente 33 mil empregos mediante concessão de incentivos fiscais, melhoria da infraestrutura de distritos industriais e Arranjos Produtivos Locais (APLs). Além disso, o Estado produziu cerca de $7 \%$ da soja mundial, $75 \%$ do algodão nacional e deteve o maior rebanho bovino do país, com economia cuja taxa de crescimento anual foi de quase dez vezes superior à média nacional - em 2003, a proporção foi de 5,0 \% para 0,54\% (MATO GROSSO, 2006).

Contudo, esse cenário de pujança econômica contrasta com o educacional, na medida em que se observa a taxa de escolarização bruta, que, em 2004, era de 17,2\%; e a taxa de escolarização líquida, de 8,1\%, abaixo da média nacional, de acordo com os dados do Instituto Brasileiro de Geografia e Estatística (IBGE) e da Pesquisa Nacional por Amostra de Domicílios (PNAD) (RISTOFF; GIOLLO, 2006). Esses dados colocam Mato Grosso em situação desfavorável. Segundo Paulo Speller, na época reitor da UFMT, o Estado"precisaria de aproximadamente mais 83 mil vagas em universidades até 2011, para se adequar às exigências do Ministério da Educação (MEC)".9

Na busca de aprimoramento educacional e capacitação profissional que permitam uma diminuição destes contrastes, (re) surge a educação profissional e tecnológica que, por meio de seus centros e institutos, contribuem igualmente para a expansão do ensino superior em Mato Grosso nesta fase de diversificação.

Desde a criação da Escola de Aprendizes Artífices (com múltiplas nomenclaturas subsequentes), até a sua transformação, em 1994, no CEFETMT, não havia a oferta de cursos de graduação. Em 2003, este quadro muda, pois o CEFETMT recebe autorização para o funcionamento dos Cursos Superiores de Graduação Tecnológica em Automação e Controle, em Desenvolvimento de Sistemas para Internet, em Gestão Ambiental e em Redes de Computadores.

No final de 2008 ocorreu a implantação do IFMT, que, assim como os demais Institutos Federais de Educação, Ciência e Tecnologia, integra (a exemplo da Reestruturação e Expansão das Universidades Federais - REUNI) o Plano de Desenvolvimento da Educação (PDE). Este plano foi lançado pelo Ministério da Educação em 2007, como parte do Plano de Aceleração do Crescimento (PAC), do governo federal, cujas ações estão propostas na expansão da rede federal para cidades-polos do território nacional. 
O IFMT nasceu, portanto, da aglutinação de dois CEFETs, o CEFET MT e o CEFET Cuiabá e de suas respectivas Unidades de Ensino Descentralizadas (UNEDs), além da Escola Agrotécnica Federal de Cáceres (EAFC).

Por fim, ressaltam-se as ações da Secretaria de Estado de Ciência e Tecnologia (SECITEC), que absorveu a gestão das unidades descentralizadas da extinta autarquia Centro de Educação Profissional e Tecnológica de Mato Grosso (CEPROTEC), com a finalidade de "ofertar educação profissional e superior de tecnologia [...]",conforme atuais projetos em estudo pelo governo do Estado.

(b) Setor privado (universidade, centro universitário, grupos educacionais e faculdades)

\section{UnIVERsidAde E Centros UnIVERSITÁRIOS}

Mato Grosso conta com apenas uma universidade privada, a Universidade de Cuiabá (UNIC), mantida pela União das Escolas Superiores de Cuiabá, fundada em 1988 (GIANEZINI, 2014).

Em 2000 e em 2004, respectivamente, assiste-se a um momento relevante no âmbito da fase de diversificação: a transformação de duas IES privadas em centros universitários. A Associação Educacional Cândido Rondon passa a se chamar Centro Universitário Cândido Rondon (UNIRONDON), as Faculdades Várzea-Grandenses de Centro Universitário de Várzea Grande (UNIVAG). A UNIRONDON, com uma unidade fora da sede, em Rondonópolis, e a UNIVAG, com cinco campi e unidades fora de sede: Rondonópolis, São Pedro da Cipa, Pontes e Lacerda, Primavera do Leste e Poconé (INEP, 2009).

[...] o setor privado busca se adaptar pelo crescimento e concentração, criando grandes estabelecimentos universitários que, no entanto, não conseguem se adaptar ao modelo universitário tradicional; [...] Ao mesmo tempo em que desenvolve estas estratégias, muitas vezes em combinação, o setor privado procura recursos institucionais e sistêmicos que possam lhe socorrer, como o crédito educativo e alterações na legislação, buscando reduzir suas exigências de conformidade aos modelos acadêmicos mais tradicionais (SCHWARTZMAN, 2001, p. 26).

Apesar da pouca tradição, em 2005, esses dois centros universitários já eram responsáveis por $27,33 \%$ das matrículas, ou seja, 12.120 matrículas, de um total de 44.345 ofertadas pelas IES privadas mato-grossenses. 


\section{Grupos Educacionals}

Observa-se nesta fase de diversificação que as políticas de expansão da educação superior "configuram-se como movimentos não ordenados, caracterizando esse nível de ensino no país como amplo e heterogêneo [...]. Promovem o redirecionamento da educação profissional e o processo crescente de privatização da educação, especialmente da educação superior. " (DOURADO, 2002, p. 04).

Nesse contexto, a partir de 2002, constata-se a emergência de novos atores no cenário do ensino superior mato-grossense. São os grupos educacionais privados (em sentido estrito, conforme o Instituto Nacional de Estudos e Pesquisas Educacionais Anísio Teixeira - INEP) que chegam ao Estado, dando início ao processo de aquisições de instituições privadas por grupos educacionais nacionais.

Em 2007, o grupo Objetivo, mantenedor da Universidade Paulista (UNIP) e presente em várias cidades do País, instala-se na capital por intermédio do Instituto Cuiabá de Educação e Cultura (ICEC - antigo IESMT).

Em 2008, o grupo Anhanguera Educacional, também de São Paulo, adquire duas IES: uma em Rondonópolis, a Faculdade do Sul de Mato Grosso (FACSUL) mantida pelo Centro de Ensino Superior de Rondonópolis (CESUR); e outra em Cuiabá, a Faculdade Centro América (FACAM), dando início a suas operações no estado.

[...] pela redução drástica de custos e preços, em concorrência muitas vezes predatória, que acaba colocando em risco sua própria razão de ser; ou pela busca de nichos de qualidade, em escala necessariamente reduzida. [...] E busca, também, abrir espaço para outras formas de atendimento a sua clientela, pelo uso de novas tecnologias de ensino, pelo estabelecimento de convênios e franquias, e novas formas de cooperação e intercâmbio nacional e internacional (SCHWARTZMAN, 2001, p. 26).

Por fim, destaca-se a criação de um grupo mato-grossense, o IUNI, considerado o $9^{\circ}$ maior do País, segundo ranking da Hoper Consultoria. Trata-se de uma holding criada pelos mantenedores da UNIC (universidade que já estava presente em diversas cidades de Mato Grosso, como mencionado anteriormente) (GIANEZINI, 2014). ${ }^{10}$ 


\section{Novas FACULDADES}

A partir do ano de 2001, observa-se a criação de novas faculdades na grande Cuiabá e "em regiões de recente colonização, como é o caso de Rondonópolis, Campo Verde e outros municípios" (SIQUEIRA, 2002, p. 119). Há também a criação de novas IES nas cidades localizadas nos principais eixos viários (BR-163 e BR-364) e/ou ligadas à modernização da agricultura e da pecuária.

Como constata Pereira (2007, p. 51), há uma emergência de restauração dos principais eixos viários de Mato Grosso que, “[...] de um lado, estão exercendo efeitos contundentes à dinamização da economia de determinados municípios e, de outro lado, esses mesmos eixos também estão atuando no sentido de ampliar as desigualdades entre as economias regionais internas".

De fato, esta contradição é, inclusive, diagnosticada pelo próprio governo estadual, e explicitada no plano de desenvolvimento do Estado de Mato Grosso (MT+20). Isso pode demonstrar a incongruência da inserção de Mato Grosso na economia globalizada.

A análise retrospectiva revela um Mato Grosso rico em recursos naturais, com uma economia dinâmica baseada na moderna agropecuária e com forte integração ao mercado mundial e à economia nacional. Dinamismo que vem, todavia, provocando forte impacto ambiental sem, no entanto, gerar a esperada melhoria da qualidade de vida da população na mesma intensidade e proporção da expansão econômica (MATO GROSSO, CD- ROM, 2006).

\section{INSTITUIÇÕES CONFESSIONAIS}

A presença da educação religiosa em Mato Grosso evidenciava-se, primeiramente, pela instalação dos padres jesuítas e, depois, com os salesianos (GIANEZINI, 2014).

Após 1977, Mato Grosso ficou sem representação no ensino superior confessional. Esse quadro de estagnação permanece até o final do século XX, quando ocorre a fundação da Faculdade Católica Rainha da Paz de Araputanga (FCARP), em 1999.

Contudo, ressalta-se que, desde o século XVIII, os salesianos tiveram importante papel educacional em Mato Grosso. Com a divisão do Estado, a IES FUCMT (futura UCDB), de responsabilidade dos padres salesianos, permaneceu no novo Estado. Os salesianos voltaram a atuar no ensino superior 
de Mato Grosso somente em 2005, com a criação da Faculdade Católica de Cuiabá, cuja categoria administrativa é de natureza privada, comunitária, confessional e filantrópica.

Por fim, em 2008, integra-se ao campo do ensino superior mato-grossense, a congregação católica La Salle, que, por muitos anos, se limitou ao Rio Grande do Sul, onde desenvolveu e consolidou suas escolas.

Com a confirmação da instalação dos Irmãos Lassalistas na cidade de Lucas do Rio Verde e com a experiência que já possuíam no ensino superior em outros estados - Amazonas (AM), Rio Grande do Sul (RS) e Rio de Janeiro (RJ) - optou-se pela incorporação (após entendimento negocial com a mantenedora local, a União das Escolas Superiores de Lucas do Rio Verde) da Faculdade de Lucas do Rio Verde (UNIVERDE). Assim, a IES passou a se chamar Faculdade La Salle de Lucas do Rio Verde (UNILASALLE), mantida agora pela Sociedade Porvir Científico, da Província Lassalista de Porto Alegre.

Porém, essa opção deu-se também pelo destaque que a UNIVERDE possuía naquele momento. Mesmo na condição de faculdade isolada, havia sido considerada a segunda melhor IES privada do Estado, de acordo com os resultados do MEC/INEP, que mediram o desempenho dos cursos e IES entre 2005 e 2007.

Em suma, a diversificação provocada pelo processo de expansão da educação superior em MT, pode ser compreendida como: (a) resultado de mudanças econômicas, que vão exigir maior (e mais diversificada) qualificação profissional e técnica, no contexto da inserção do Estado em uma sociedade globalizada, com base na informação; e (b) decorrência, segundo a natureza cultural, da possibilidade de ascensão social por meio da formação em nível superior.

Para atender a essas exigências diversas, Mato Grosso vai contar com a presença de todos os tipos de IES, tanto por organização acadêmica: universidade, centro universitário, faculdade e instituto de educação, quanto por categoria administrativa: pública (municipal, estadual e federal); e privada (filantrópica, confessional ou comunitária; e particular em sentido estrito).

Conclui-se assim, na análise desta fase de diversificação, que a mesma distingue-se das demais pelo fato de representar uma (nova) ruptura com o princípio de referência territorial dos distritos geoeducacionais como base da organização e diversificação da oferta de ensino superior. 


\section{CONSIDERAÇÕES FINAIS}

As informações, dados e análises contidas na pesquisa auxiliaram na compreensão do processo de expansão do ensino superior em Mato Grosso que ocorreu tardiamente se comparado aos demais estados brasileiros das regiões Sul, Sudeste e Nordeste.

Entretanto, é possível constatar a existência de fases e analisar essa expansão, em especial, das últimas quatro décadas que transformou o campo educacional de Mato Grosso, acompanhando as demais transformações socioeconômicas (mudança da matriz econômica), culturais (migrações) e políticas (divisão territorial) experimentadas pelo estado. A partir de uma visão crítica, observa-se que:

(i) Na fase de instalação, a falta de continuidade das iniciativas e ações ligadas ao ensino superior - ora inócuas, ora contraproducentes - evidenciam a fragilidade educacional e contribuem para o surgimento do descontentamento da parte Sul do Estado (até então subordinada à Cuiabá), contribuindo para o processo de divisão do Estado; (ii) Na fase da centralização, notam-se as principais implicações, no ensino superior do antigo estado de Mato Grosso. Em primeiro lugar, a criação da UFMT (1970); em segundo lugar, a instalação do Campus Avançado do Projeto Rondon (1973), em Cáceres; e em terceiro lugar, a criação do IESC (1978), que se transformaria em universidade (UNEMAT) anos depois. Constatou-se também nessa fase, a existência de uma centralização bipolarizada, que pode ser dividida em dois momentos, sendo o primeiro entre Cuiabá e Campo Grande e o segundo entre Cuiabá e Cáceres; (iii) $\mathrm{Na}$ fase de interiorização, observou-se a disputa das duas universidades públicas que se voltaram, ao mesmo tempo, para múltiplas direções. Com estratégias diferentes, mas com o mesmo objetivo: garantir novos espaços geográficos por meio da expansão; (iv) Na fase da diversificação, constata-se a pluralidade de iniciativas e ações que trazem para o cenário mato-grossense a diversidade já existente nos estados mais desenvolvidos do Brasil. Da criação de novas faculdades (que ocuparam os espaços remanescentes do interior e da capital), passando pelo IFECT (novo arranjo educacional), pelas instituições universitárias privadas (universidades e centros universitários), pelos grupos educacionais (com ação essencialmente empresarial) e pelas instituições confessionais (religiosas), percebe-se uma nova disposição.

Por fim, com relação às duas universidades públicas conclui-se que a "corrida" por novos espaços se sobrepôs aos anseios de muitos agentes sociais engajados nas lutas em prol da defesa da universidade, seja "pela ou para" a 
UFMT, seja"para ou pela"UNEMAT. Era o processo de expansão indo, ao mesmo tempo, "ao encontro do" e "de encontro ao" engajamento das lideranças.

\section{HIGHER EDUCATION IN THE BRAZILIAN LEGAL AMAZON: THE CASE OF THE STATE OF MATO GROSSO}

ABSTRACT: In recent years, the effects of globalization are changing the production system, the ways of social interaction, as well as the use of knowledge and information. Based on this perspective, this study intended to analyze the expansion of Higher Education regarding different phases (implementation, centralization, interiorization, and diversification) in the region of the Brazilian Legal Amazon, in the state of Mato Grosso (MT), and the development of this State (before and after its territorial division). Methodologically, it was sought to: a) briefly describe the historical and socioeconomic background that changed and influenced the course of higher education in MT; and b) address the scenario from the twentieth century to the present day, focused on the implementation of the first higher education institutions, the territorial division and their reflections in MT, as well as the diversification of teaching in the early twenty-first century.

KeYwoRDs: Higher Education. University. Brazil. Expansion.

\section{EDUCACIÓN SUPERIOR EN LA AMAZONIA LEGAL BRASILEÑA: EL CASO DE LA EXPANSIÓN EN LA PROVINCIA DE MATO GROSSO}

Resumen: En las últimas décadas los efectos de la globalización están cambiando los modos de producción, la forma de socialización y el uso de los conocimientos. Es a partir de esta perspectiva que se pretendió analizar la expansión de la educación superior en diferentes fases (instalación, centralización, internalización y diversificación) relacionadas con el campo de la educación en la Amazonia Legal de la provincia de Mato Grosso (MT), y al desarrollo del estado (antes y después de su división territorial). Metodológicamente, se buscó: (a) describir brevemente los antecedentes históricos y socio-económicos, en que ocurrieron las transformaciones que han influido en el curso de la educación superior de Mato Grosso; y (b) Tratar del escenario del comienzo del siglo XX hasta nuestros días, abarcando las fases de la educación superior en MT: de la instalación de las primeras Instituciones de Educación Superior (IES), que pasa 
a través de la división territorial y de su reflexión en MT, hasta la diversificación de la enseñanza que ocrrurió el comienzo del siglo XXI.

PalabRAs Clave: Educación superior. Universidad. Brasil. Expansión.

\section{NOTAS}

1) Cabe salientar que essas categorias foram aplicadas em outro estudo no Rio Grande do Sul, por Neves (1993), e reaplicadas, de forma adaptada, à realidade do estado de Mato Grosso, por Gianezini (2009).

2) O processo de divisão do estado de Mato Grosso findou com a instalação oficial do Estado de Mato Grosso do Sul e da Assembleia Estadual Constituinte em $1^{\circ}$ de janeiro de 1979 (BITTAR; RODRÍGUEZ; ALMEIDA, 2006).

3) A UEMT foi criada pela Lei Estadual n².947, de 16 de setembro de 1969. Até 1979, havia criado quatro campi: Corumbá, Três Lagoas, Aquidauana e Dourados.

4) Esta pergunta foi utilizada por Oliveira (2009), no caso, específico, do Rio Grande do Sul em relação à Universidade do Estado do Rio Grande do Sul (UERGS), fundada em 2001.

5) Consultar as teses de Beraldo (2005) e Alonso (2005).

6) Projeto de Desenvolvimento Institucional.

7) Sua sede fica na cidade de Nova Mutum. Era mantida pela Fundação Municipal de Ensino Superior de Nova Mutum (FUMESUNM). A FAMUNM passou a se chamar UNINOVA pela Lei Municipal $n^{\circ} 778$, de $1^{\circ}$ de fevereiro de 2003. Recentemente essa IES foi incorporada pela UNEMAT tal como ocorreu em Tangará da Serra com a CESUT.

8) Campus Universitário de Sinop foi criado como primeiro Núcleo Pedagógico pelo Decreto Governamental n².720, de 09 de julho de 1991. Transformou-se em campi pela Lei $\mathrm{n}^{\circ}$ 30, de 15 de dezembro de 1993 (MATO GROSSO-SEPLAN, 2007; MEDEIROS, 2008; ZATTAR, 2008).

9) Optou-se, aqui, por apresentar o nome do reitor da UFMT na época, considerando que essa informação é de domínio público - conferida na abertura do Fórum “Construção do Plano Estratégico para o atendimento da Formação Inicial de Professores em Mato Grosso: Debate entre as Licenciaturas", realizado, na UFMT, em julho de 2008.

10) Para saber mais a respeito das transformações recentes da UNIC, do luni e da Kroton vide Gianezini (2014). 


\section{REFERÊNCIAS}

ALONSO, K. M. Formação de professores em exercício, educação a distância e a consolidação de um projeto de formação: o caso da UFMT. Tese de Doutorado, Unicamp, 2005.

BERALDO, T. M. L. Caminhos do curso de pedagogia na modalidade parcelada: percalços e avanços de uma experiência desenvolvida pela UFMT no interior de Mato Grosso. Tese de Doutorado. Campinas, PPPGEDU, 2005.

BITTAR, M.; RODRÍGUES, M.; ALMEIDA, C. B. A educação superior em Mato Grosso do Sul. In: A Educação Superior Brasileira: 1991 - 2004, Mato Grosso do Sul. Brasília, INEP, 2006.

CASTRILLÓN FERNANDEZ. A. J. Do cerrado à Amazônia: estruturas sociais da economia da soja em Mato Grosso. Tese de Doutorado. Porto Alegre: UFRGS/PPGDR, 2007.

CATELLI, R. E. A Comissão Rondon e a construção da imagem do interior do Brasil. In: Cadernos de Ciências Humanas - Especiaria. v. 10, n.17, jan./jun. 2007.

DORILEO, B. P. O Ensino Superior em Mato Grosso: até a implantação da UFMT. Campinas: Komedi, 2005.

DORILEO, B. P. Raízes da Universidade de Mato Grosso ano X. Prolegômenos, 1982.

DOURADO, L. F. Reforma do Estado e as políticas para a educação superior no Brasil nos anos 90. Educação \& Sociedade: Revista de Ciência da Educação/CEDES. v. 23, 2002.

FERNANDES, E. B. Expansão universitária em Mato Grosso do Sul: 1979-2001. Dissertação de Mestrado, Campo Grande: UCDB, 2003.

FERREIRA, J. C. V. Enciclopédia llustrada de Mato Grosso. Cuiabá: Buriti, 2004.

FRANCISCO, A. J. Apóstolos do progresso: a prática educativa salesiana no processo de modernização em Mato Grosso (1894-1919). Dissertação de Mestrado, Cuiabá, PPGEDU, 1998.

GIANEZINI, K. Educação e Sociedade: a expansão do ensino superior jurídico e o acesso de minorias étnicas. 2014. 300f. Tese (Doutorado em Educação) — Programa de Pós-Graduação em Educação, Universidade Federal do Rio Grande do Sul, Porto Alegre, 2014.

GIANEZINI, K. O Processo de Expansão do Ensino Superior em Mato Grosso. 2009. 250f. Dissertação (Mestrado em Sociologia) — Programa de Pós-Graduação em Sociologia, Universidade Federal do Rio Grande do Sul, Porto Alegre, 2009.

HELD, D; McGREW, A. Prós e contras da globalização. Rio de Janeiro, Jorge Zahar Editor, 2001. 
INSTITUTO NACIONAL DE ESTUDOS E PESQUISAS EDUCACIONAIS - INEP. Disponível em: <http://www.educacaosuperior.inep.gov.br/funcional/info_ies_new.asp? pIES=794>. Acesso em: 24 abr. 2009.

MATO GROSSO. Plano de Desenvolvimento do Estado de Mato Grosso, MT + 20. CD ROM, 2006.

MEDEIROS, I. A. Inclusão social na universidade: experiências na UNEMAT. Dissertação de Mestrado. UNICAMP, São Paulo, 2008.

MOURA, C. F. Médicos e Cirurgiões em Mato Grosso no século XVIII e início do XIX. EdUFMT: Cuiabá, 1978.

NASCIMENTO, A. L. do. Acesso à Educação Superior: limites de uma possibilidade. Cuiabá, 1998. Dissertação (Mestrado em Educação) - UFMT, 1998.

NEVES, C. E. B. O Ensino Superior no Rio Grande do Sul. In: Enciclopédia de Pedagogia Universitária e Pesquisa: Para revitalização do ensino e do aprender na Universidade. Relatório Final. Parte I. Porto Alegre: UFRGS, 1993.

OLIVEIRA, R. Desterritorialización y localización de la enseñanza superior: En busca de un marco conceptual para la planificación de la enseñanza superior teniendo en cuenta el desarrollo regional. Revista de Universidad y Sociedad del Conocimiento, Barcelona, v. 4, n. 2, p. 2-4, 2007. Disponível em:<http://www.uoc.edu/rusc/4/2/dt/ esp/oliveira.pdf>. Acesso em: 7 maio 2009.

OLIVEIRA, R. 1980-1989: A "década perdida". In: Cronologia do Desenvolvimento Científico, Tecnológico e Industrial Brasileiro 1938 - 2003: homenagem do Ministério do Desenvolvimento, Indústria e Comércio Exterior e do Serviço Brasileiro de Apoio às Micro e Pequenas Empresas pelos 65 anos da Confederação Nacional da Indústria / Medalha do Conhecimento 2003 / Ministério do Desenvolvimento Indústria e Comércio Exterior; Serviço Brasileiro de Apoio às Micro e Pequenas Empresas. Brasília: $\mathrm{MDIC/STI;} \mathrm{IEL/CNI,} 2005$.

OLIVEN, A. C. Histórico da Educação Superior. In: A Educação Superior no Brasil. Brasília, CAPES, 2002.

PEREIRA, B. D. Mato Grosso: Principais eixos viários e a modernização da agricultura. Cuiabá: EdUFMT, 2007.

RIBEIRO, M. L. S. R. História da Educação Brasileira. São Paulo: Cortez \& Moraes. 2. ed., 1979.

RISTOFF, D.; GIOLO J. Introdução: A educação superior no Brasil: Panorama geral. In: . (Org.). Educação Superior Brasileira 1991-2004. Brasília: INEP/MEC. 2006.

SANTOS, J. V. T. Matuchos: exclusão e lutas. Petrópolis: Vozes, 1993.

SCHWARTZMAN, S. A revolução silenciosa do Ensino Superior. In: DURHAM, E.; SAMPAIO, H. (Org.) o Ensino Superior em Transformação. São Paulo: NUPES, 2001. 
SILVA, J. V. A Divisão do Estado de Mato Grosso: uma visão histórica (1892 - 1977). EdUFMT: Cuiabá, 1996.

SIQUEIRA, E. M. História de Mato Grosso: da ancestralidade aos dias atuais. Cuiabá: Entrelinhas, 2002.

UFMT. Plano de Desenvolvimento Institucional. (PDI) Cuiabá. 2008. Mimeo.

UNEMAT. Plano de Desenvolvimento Institucional. (PDI) Cáceres. 2008. Mimeo.

VELOSO, T. C. M. A.; SILVA, M. das G. G. M. da; BERALDO, T. M. Educação superior em Mato Grosso: 1991 - 2004. In: A Educação Superior Brasileira: 1991 - 2004, Mato Grosso. Brasília, INEP, 2006.

ZATTAR, N. B. da S.; TEIXEIRA, D. T.; ARTIOLI, L. B. UNEMAT 30 anos: Pelos Caminhos de Mato Grosso. Cáceres [MT]: Editora da UNEMAT, 2008.

ZATTAR, N. Do IESC à UNEMAT: uma história plural 1978 - 2008. Cáceres [MT]: Editora da UNEMAT, 2008.

Kelly GianeZINI: Doutora em Educação pela Universidade Federal do Rio Grande do Sul (UFRGS), com estágio de doutoramento sanduíche pela University of California Los Angeles (UCLA). Possui Licenciatura em Sociologia pela Universidade Regional do Noroeste do estado do Rio Grande do Sul (UNIJUI), Bacharelado em Ciências Sociais e Mestrado em Sociologia, ambos pela UFRGS. Também é graduada em Direito pela Pontifícia Universidade Católica do Rio Grande do Sul (PUCRS).

E-mail: kellygianezini@terra.com.br 